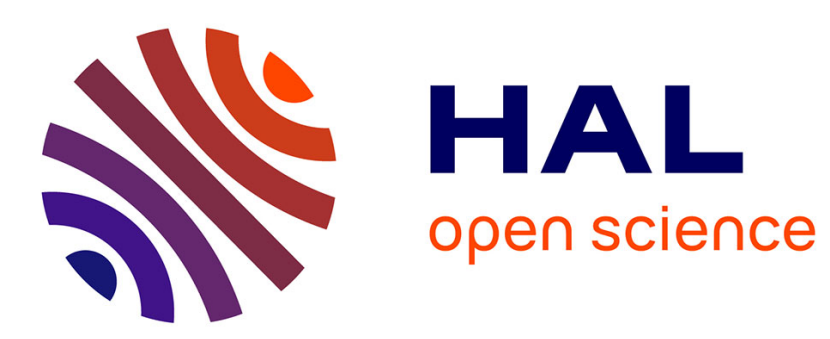

\title{
GRAIN BOUNDARY CHEMICAL ANALYSIS BY SIMS
}

\author{
Jérôme Lang, F. Degrève, N. Thorne
}

\section{To cite this version:}

Jérôme Lang, F. Degrève, N. Thorne. GRAIN BOUNDARY CHEMICAL ANALYSIS BY SIMS. Journal de Physique Colloques, 1987, 48 (C3), pp.C3-693-C3-698. 10.1051/jphyscol:1987380 . jpa00226611

\section{HAL Id: jpa-00226611 https://hal.science/jpa-00226611}

Submitted on 1 Jan 1987

HAL is a multi-disciplinary open access archive for the deposit and dissemination of scientific research documents, whether they are published or not. The documents may come from teaching and research institutions in France or abroad, or from public or private research centers.
L'archive ouverte pluridisciplinaire HAL, est destinée au dépôt et à la diffusion de documents scientifiques de niveau recherche, publiés ou non, émanant des établissements d'enseignement et de recherche français ou étrangers, des laboratoires publics ou privés. 


\title{
GRAIN BOUNDARY CHEMICAL ANALYSIS BY SIMS
}

\author{
J.M. LANG, F. DEGREVE and N.A. THORNE \\ Cégédur-Péchiney, Centre de Recherche et Dêveloppement, \\ B.P. 27, F-38340 Voreppe, France
}

\begin{abstract}
Al-Li alloys are prone to severe intergranular fracture if certain metallurgical parameters are not controlled. The concentration level of trace elements, notably Na which is likely to segregate at grain boundaries, may well be of critical importance. To investigate the possible role of $\mathrm{Na}$ a novel approach to grain boundary chemical analysis using SIMS has been developed. This general method, based on depth profiles performed on controlled bevelled sections, is demonstrated for an Al-Li alloy containing $40 \mu \mathrm{g} / \mathrm{g}$ of $\mathrm{Na}$. It would appear that $\mathrm{Na}$ does not form a continuous grain boundary film, but may be found in small nodules within the grain boundary regions. The intergranular fracture mode observed for this specimen cannot therefore be directly attributed to the abnormal Na concentration.
\end{abstract}

\section{INTRODUCTION}

Sodium is known to have a deleterious effect on the toughness and ductility of $\mathrm{Al}$ alloys. The same effect has been reported ${ }^{(1)(2)}$ in Al-Li alloys. This point needs to be investigated in more detail for this new class of alloys, since (1) $\mathrm{Na}$ is a possible impurity of $\mathrm{Li}$ and (2) $\mathrm{Al}-\mathrm{Li}$ alloys seem to be more aggressive than conventional alloys to furnace linings, presenting a further potential source of Na contamination.

This paper reports on a novel experimental technique for the general analysis of grain boundary segregation. The technique is demonstrated for the case of an Al-Li alloy containing an abnormally high $\mathrm{Na}$ content of $40 \mu \mathrm{g} / \mathrm{g}$ and exhibiting an intergranular fracture mode.

\section{EXPERIMENTAL PROCEDURE}

\subsection{Specimen preparation}

An Al-Li alloy ( $\mathrm{Li} 2.8 \%$; $\mathrm{Cu} 1.5 \% ; \mathrm{Mg} 0.9 \% ; \mathrm{Zr} 0.1 \%$ ) with $40 \mu \mathrm{g} / \mathrm{g}$ of $\mathrm{Na}$ was cast, homogenised at $800^{\circ} \mathrm{K}$ for $24 \mathrm{~h}$, hot extruded and subsequently heat-treated to the T851 temper. The alloy thus prepared presented elongated grains with well defined flat grain boundaries in the long transverse direction. Fracture occurs along these grain boundaries at low stresses, as revealed by the SEM micrograph of Figure 1.

For subsequent SIMS analysis, a bevelled section was prepared by polishing at an angle of about $2^{\circ}$ with respect to the long-transverse plane, as schematised in Figure 2 a) and b). Two types of grain boundary can be seen to intersect the polished bevel plane $X_{0}$ in Figure $2 b$; type $B$ which make a large angle with respect to the bevel plane, and type A with only a small angle equivalent to the bevel angle of $2^{\circ}$. Type A are suitable for the SIMS analysis since a grain boundary, in Figure $2 \mathrm{~b}$ the boundary between grains 1 and 3, lies just beneath the surface. A standard SIMS depth profile performed just to the right of point $A$ will therefore allow the chemical analysis of the boundary between grain 1 and 3 . 


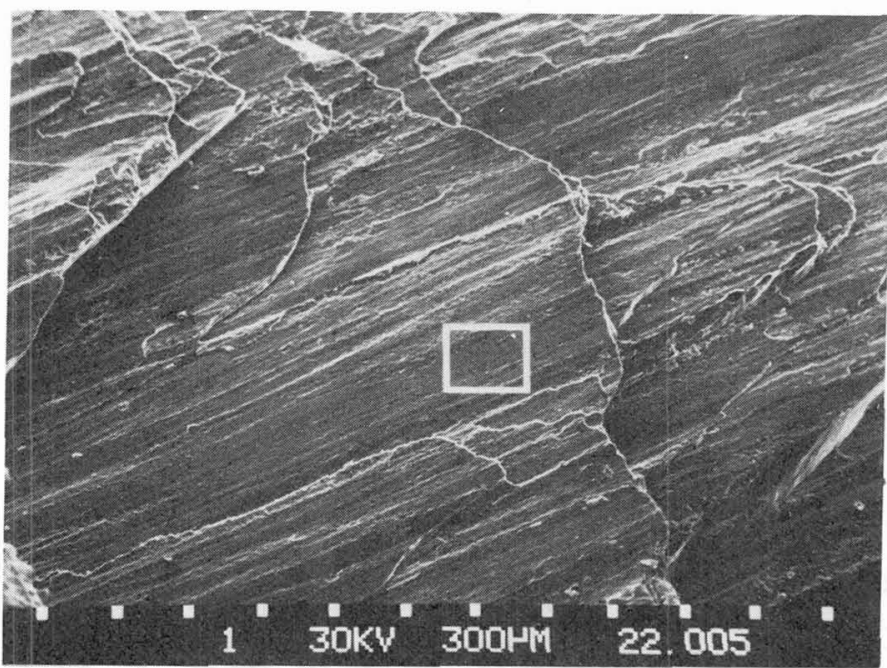

Figure 1: Scanning electron micrograph of the fracture surface showing an intergranular fracture mode. The grains are flat, elongated and almost parrallel to the sample surface.

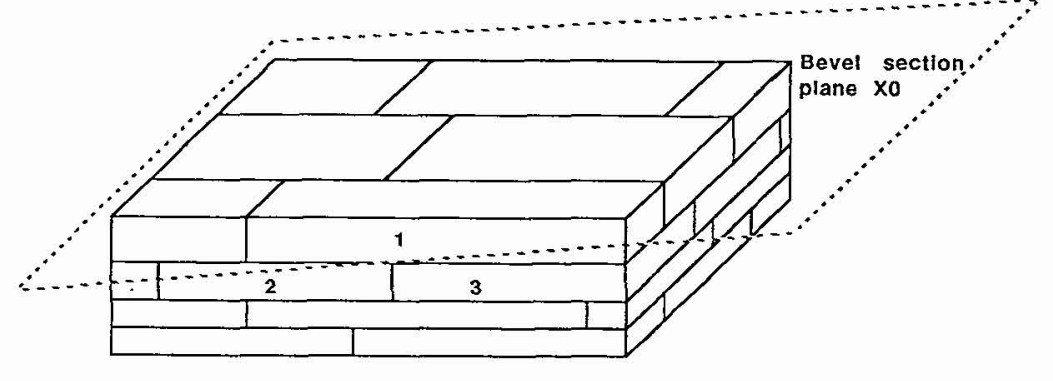

a)

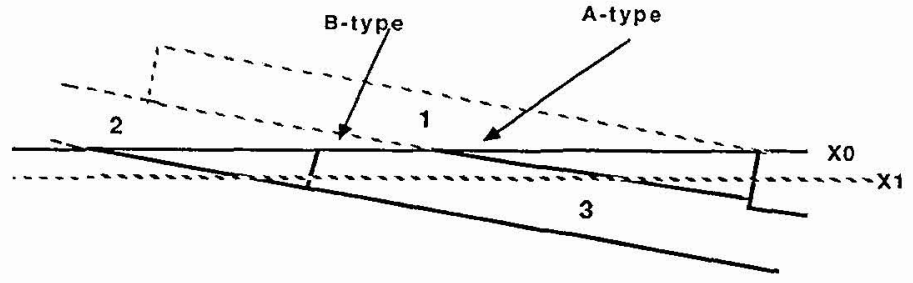

b)

Figure $2:$ Schematic diagram of the sample with respect to the polished bevel section, and showing the elongated flat grains:

a) general view

b) cross sectionnal view showing the bevel plane $X_{0}$ after polishing and $X_{1}$ after slight ion etching. Also illustrated are A-type boundaries suitable for SIMS depth profile analysis and B-type boundaries more suitable for TEM or EPMA studies. 
At this point some of the advantages ot this technique are readily seen :

- the grain boundary is analysed without having been previously exposed to air or vacuum as is the case for conventional Auger analysis where the sample must be pre-fractured.

- the technique is suitable for materials which do not readily fracture along grain boundaries.

- the excellent depth resolution of SIMS $(<10 \mathrm{~mm}$ ) can be put to full use during sputtering across the grain boundary.The depth resolution is defined principally by the bevel angle.

- Grain boundary analysis is performed with the excellent sensitivity inherent of SIMS: $10^{-6}$ to $10^{-9} \mathrm{~g} / \mathrm{g}$ compared to $10^{-2} \mathrm{~g} / \mathrm{g}$ in Auger analysis.

Type B boundaries are generally used for electron microprobe or transmission electron microscopy work. In extreme cases of grain boundary segregation they may be used for direct SIMS imaging studies, although the lateral resolution in the imaging mode of about $1 \mu \mathrm{m}$ is generally insufficient.

\subsection{Identification and selection of the analysis zone}

To correctly identify A-type grain boundaries suitable for analysis the SIMS imaging mode is used. $\mathrm{Ar}^{+}$primary ion bombardment under high vacuum results in a crystallographic contrast in the matrix ion image $\left({ }^{27} \mathrm{Al}^{+}\right.$in this case). This phenomenon is due to different sputtering rates from grain to grain induced by varying degrees of channelling (and hence penetration) of the primary $\mathrm{Ar}^{+}$ beam along the crystallographic planes. A-type grains are recognised as, during sputtering, they "move" across the image. For the case of Fig. $2 b$, when sputtering from plane $X_{0}$ to $X_{1}$, the A-type boundaries move from left to right, while the B-type boundary remains virtually fixed. This is illustrated in fig. 3 , which corresponds to $27 \mathrm{Al}^{+}$images obtained in the same zone at the initial stages (3a) and after several minutes of sputtering ( $3 b$ ). The two grains apparent in the figure correspond to an A-type boundary, the bright grain receding towards the top of the image. The black rectangle indicates a zone suitable for depth profiling.
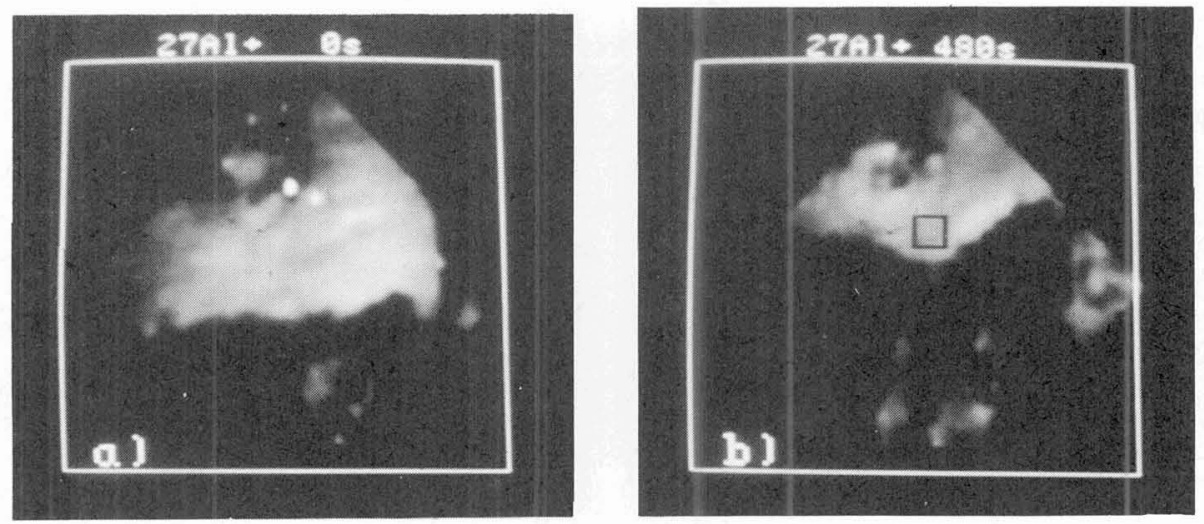

$50 \mu \mathrm{m}$

Figure 3 : Localisation in the SIMS imaging mode of A-type grains and hence the correct zone for subsequent depth profiling across the grain boundary lying just beneath the bevel plane:

a) $27 \mathrm{Al}^{+}$matrix ion image at the initial stage of ion bombardment. The crystallographic contrast reveals two grains at an A-type boundary.

b) The same zone after several minutes of ion etching. The bright grain has receded towards the top of the image confirming that it is an A-type boundary. The black rectangle indicates the zone selected for SIMS depth profiling. 


\subsection{SIMS depth profiling across a grain boundary}

After identification and selection of the analysis zone (several $\mu \mathrm{m}^{2}$ ) depth profiles are performed in virtually the standard manner. A CAMECA IMS $3 \mathrm{f}$ ion microscope was used in the following example. The sample surface was not completely saturated with oxygen (introduced in-situ near to the sample surface), a common practice which maximises and stabilises the secondary ion signals. This is because the resultant formation of an amorphous surface oxide supresses the crystallographic contrast, and subsequent localisation of the grain boundary in the depth profiles would not be possible.To overcome this, an intermediate oxygen partial pressure was maintained, allowing a compromise between the secondary ion signal intensity and residual crystallographic contrast. The change in the matrix ion signal when passing from one grain to another therefore allows localisation of the grain boundary.

A final consideration when performing SIMS analysis of complex materials is the possibility of "interference" peaks being present at the nominal mass of interest. These are commonly secondary molecular ions which can only be differentiated from monoatomic ions by their mass defect. High mass resolution is therefore indispensable either as a control or as a necessary working condition. In the present case, for the analysis of monoisotopic $\mathrm{Na}$, two peaks are likely at 23 daltons: the ${ }^{23} \mathrm{Na}^{+}$ (22.9898 daltons) ion has a possible interference peak of ${ }^{7} \mathrm{Li}^{16} \mathrm{O}^{+}(23.0109)$. A mass resolution $\mathrm{M} / \Delta \mathrm{M}$ of $>1100$ is necessary to seperate these two peaks and allow the correct analysis of Na.

\section{RESULTS AND DISCUSSION}

Figure 4 presents a high mass resolution mass spectrum $(M / \Delta M \approx 4000)$ obtained from the Al-Li sample at the mass 23 and clearly showing the relative intensities of the two peaks $\mathrm{LiO}^{+}$and $\mathrm{Na}^{+}$. Depth profiles were subsequently performed at high mass resolution, after manual calibration of the spectrometer so as to eliminate any contribution from $\mathrm{LiO}^{+}$.

A typical depth profile crossing a grain boundary located by the above procedure is illustrated in Figure 5. The grain boundary, localised at the deflection in the matrix $27 \mathrm{Al}^{+}$ion signal (and $7 \mathrm{Li}^{+}$ from the matrix) is indicated. The profile indicates that no continuous $\mathrm{Na}$ film exists at the grain boundary (for a global $\mathrm{Na}$ concentration of $40 \mu \mathrm{g} / \mathrm{g}$ ). Instead, the $\mathrm{Na}$ is found in the form of small nodules of a few microns in diameter, their distribution being apparently more concentrated in the grain boundary region.

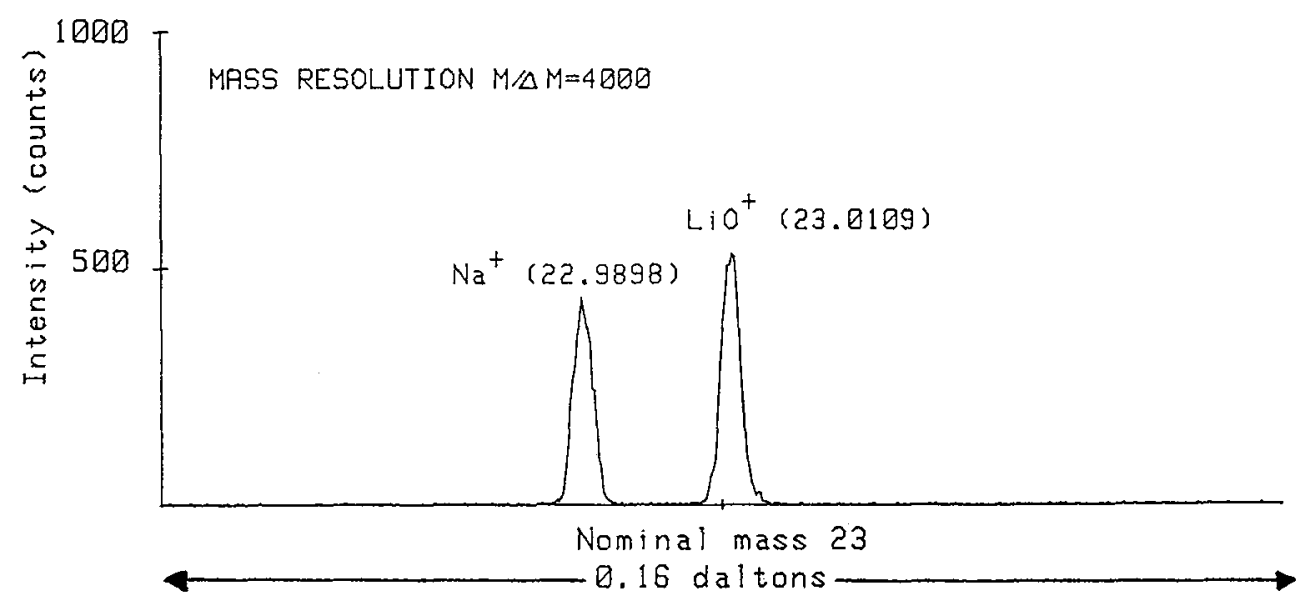

Figure 4: High mass resolution mass spectra revealing the presence at the mass 23 of two peaks, ${ }^{7} \mathrm{Li}^{16} \mathrm{O}^{+}$and ${ }^{23} \mathrm{Na}^{+}$. The correct analysis of $\mathrm{Na}$ in $\mathrm{Al}-\mathrm{Li}$ alloys therefore requires high mass resolution SIMS $(M / \Delta M>1100)$ 


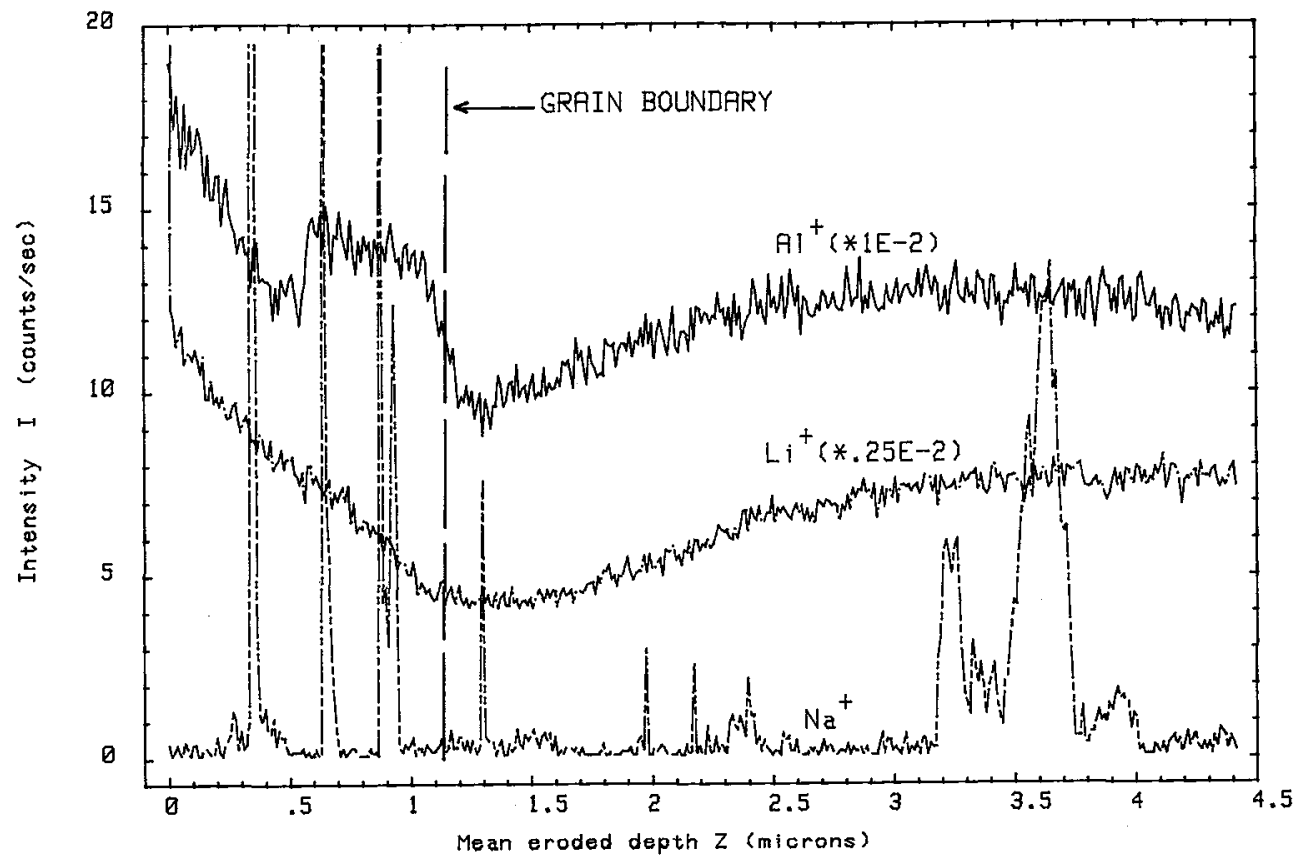

Figure 5: Typical depth profile obtained across a grain boundary (localised by the deflection in the matrix $27 \mathrm{Al}^{+}$ion due to a residual crystallographic contrast). The Na appears to be present in the form of small nodules, the density of which would appear to be greater near the grain boundary region.

A final verification was performed at high mass resolution to ensure the positive identification of $\mathrm{Na}$. While depth profiling at high mass resolution across two nodules, both the ${ }^{23} \mathrm{Na}^{+}$and ${ }^{7} \mathrm{Li}$ $16 \mathrm{O}^{+}$secondary ion signals were recorded. Fig.6 presents the resultant depth profiles, clearly illustrating the positive identification of $\mathrm{Na}:$ the $\mathrm{LiO}^{+}$ion signal remains constant throughout and is characteristic of the $\mathrm{Li}$ in the matrix.

The apparent lack of a continuous Na rich grain boundary film would seem to exclude any correlation between an intergranular fracture mode and $\mathrm{Na}$ contents of $\leq 40 \mu \mathrm{g} / \mathrm{g}$. Additional SIMS studies in the imaging mode have since shown that the number of $\mathrm{Na}$ rich particles increases with the global Na concentration from 1 to $200 \mu \mathrm{g} / \mathrm{g}$ in doped Al-Li alloys, while the Na concentration in the matrix remains virtually constant within this same concentration range.

\section{CONCLUSIONS}

SIMS chemical analysis of grain boundaries is feasible using a novel technique based on depth profiles performed on carefully prepared bevelled sections. This general technique has been applied to the analysis of $\mathrm{Na}$ within the grain boundary region of an $\mathrm{Al}-\mathrm{Li}$ alloy having a global $\mathrm{Na}$ concentration of $40 \mu \mathrm{g} / \mathrm{g}$. Although the material exhibited an intergranular fracture mode, no correlation could be found with respect to $\mathrm{Na}$ segregation at the grain boundaries. Although $\mathrm{Na}$ was positively identified, it was found to be present in nodules a few $\mu \mathrm{m}$ in diameter instead of a continuous $\mathrm{Na}$ rich intergranular film. It would, however, appear that these nodules are more frequent within the grain boundary regions. 


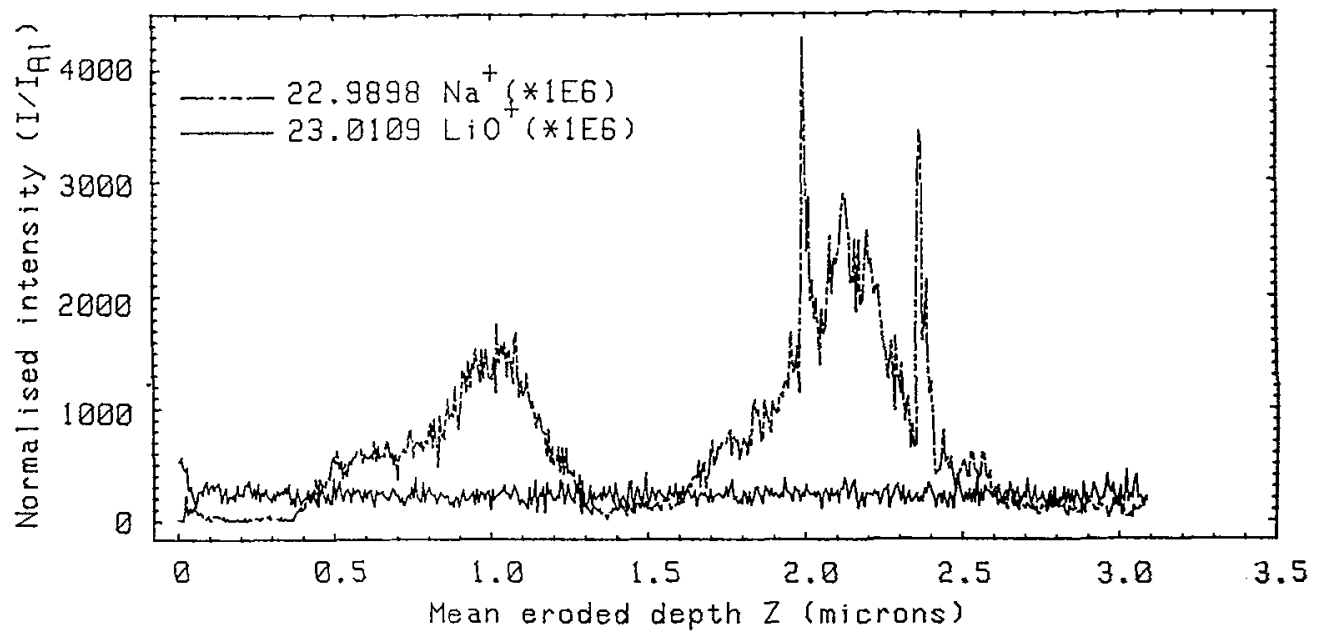

Figure 6: The positive identification of $\mathrm{Na}$ was confirmed by performing a high mass resolution depth profile across two "nodules", while measuring both the ${ }^{23} \mathrm{Na}^{+}$and ${ }^{7} \mathrm{Li}^{16} \mathrm{O}^{+}$ion signalswith respect to the matrix ${ }^{27} \mathrm{Al}^{+}$. The ${ }^{7} \mathrm{Li}^{16} \mathrm{O}^{+}$signal remains constant while that of ${ }^{23} \mathrm{Na}^{+}$increases.

\section{Acknowledgements}

The authors would like to thank the technical assistance of M. Dussoulliez.

\section{References}

1) Kersker M.M, Miller A.C. and Vasudevan, A.K., "Proceedings of the Second International Al-Li Conference", Published by AIME, 1984, Edited by Stark Jr.E.A. and Sanders Jr. J.H., p181

2) Webster D., in Al-Li III, The Institute of Metals, 1986, Edited by Baker C., Gregson P.J., Harris S.J. and Peel C.J. p 602 